\title{
PENERAPAN MODEL RCCDE UNTUK MENINGKATKAN HASIL BELAJAR SISWA MENGGUNAKAN ALAT PERAGA DI SMP 01 ISLAM JEMBER
}

\author{
${ }^{1}$ Jamaliyah, ${ }^{2}$ Siti Roudlotul Hikamah, ${ }^{3}$ Umi Nurjanah \\ ${ }_{123}$ Pendidikan Biologi, Universitas Islam Jember \\ 1jamaliyah254@gmail.com, 2sitihikamah@yahoo.com,3kholidumi@gmail.com
}

\begin{abstract}
ABSTRAK
Model pembelajaran merupakan salah satu alat bantu yang digunakan oleh guru dalam proses pembelajaran. Masalah dalam penelitian ini adalah hasil belajar siswa rendah, dimana siswa tidak memiliki semangat dan motivasi untuk belajar dan nilai hasil belajar siswa masih banyak yang di bawah KKM, terutama pada saat ulangan harian. Jenis penelitian ini menggunakan PTK, dengan pengumpulan data menggunakan data kuantitatif yang berasal dari tes kognitif hasil belajar siswa. Dengan nilai rata-rata kognitif siswa pada siklus 1 sebesar 76. Pada siklus II diperoleh rata-rata nilai kognitif siswa sejumlah 81, maka terjadi peningkatan sejumlah 5\%. Penerapan model menggunakan model RCCDE (Reading Concept Map Connection Discussion Evaluation) melalui media alat peraga sangat efektif dan dapat meningkatkan hasil belajar siswa sehingga dapat membantu dalam keberhasilan proses pembelajaran.
\end{abstract}

Kata kunci: Alat peraga, Hasil belajar, Model RCCDE.

\begin{abstract}
Learning model is one of the tools that used by the teacher in learning process. The problem in this research is the learning outcomes of students are low, where the students do not have enthusiasm and motivation to learn and the value of students' learning outcomes is still much below the KKM, especially in daily tests. This type of research uses PTK, with data collection using quantitative data derived from cognitive tests of students' learning outcomes. By the average cognitive score of students in cycle 1 of 76. In the second cycle it was obtained that the average cognitive score of students was 81, so there was an increase of 5\%. The application of model by using RCCDE (Reading Concept Map Connection Discussion Evaluation) model through the media of teaching aids is very effective and it can improve students' learning outcomes, so that it can help the success of learning process
\end{abstract}

Keywords: Teeaching aids, Learning Outcomes, RCCDE model.

\section{PENDAHULUAN}

Motivasi belajar merupakan salah satu faktor yang turut menentukan keefektifan dalam pembelajaran, seorang pendidik akan belajar dengan baik jika ada faktor pendorongnya yaitu motivasi belajar. Motivasi belajar yang dimiliki siswa-siswa dalam setiap kegiatan pembelajaran sangat berperan untuk meningkatkan hasil belajar siswa dalam mata pelajaran tertentu (Nashar, 2004). Peran guru dalam proses pembelajaran sangatlah penting, bagaimana guru melakukan usaha untuk dapat menumbuhkan motivasi dan semangat agar siswa belajar dengan baik. Motivasi belajar bukan hanya penting karena menjadi faktor penyebab belajar, namun juga memperlancar belajar dan hasil belajar (Ani Catherina Tri, 2006). Dalam hal ini motivasi tidak dikatakan baik, apabila tujuan yang diinginkan itu tidak baik (Baedowi Ahmad, 2015). Motivasi memiliki peranan dalam proses pembelajaran karena tanpa motivasi siswa tidak akan ada semangat dalam belajar. Perlu beberapa hal untuk miningkatkan 
motivasi belajar diantaranya menggunakan metode, model, dan media pembelajaran yang bervariasi.

Model pembelajaran suatu perancang atau pola yang digunakan sebagai pedoman dalam pemecahan pembelajaran di dalam kelas atau pembelajaran di luar kelas sebagai faktor pendukung pembelajaran agar membuat siswa turut aktif dalam proses pembelajaran. Model pembelajaran merupakan suatu pola yang digunakan sebagai pedoman dalam merencanakan pembelajaran di kelas maupun tutorial saat melaksanakan proses pembelajaran atau tahapan-tahapan pembelajaran (Suprianto Agus, 2010). Model RCCDE menggunakan sintak pembelajaran: Reading, Concept Map, Connection, Discussion, Evaluation. Masingmasing tahapan dapat diuraikan sebagai berikut.

\section{$\mathbf{R}=$ (Reading)}

Membaca adalah sebuah komponen dasar seseorang bisa memiliki pemahaman atau suatu pengetahuan yang lebih, dan dapat meningkatkan daya ingat yang tinggi. Karena dengan membaca seseorang akan menjadi semakin kaya akan pengetahuan (Yunus Abidin, 2012). Dalam penelitian ini maksud dari membaca adalah mempelajari terlebih dahulu materi yang akan di sampaikan oleh guru sebelum proses pembelajaran.

\section{$\mathrm{C}=($ Cancept Map $)$}

Konsep Map merupakan sebuah sistem alami yang dilakukan oleh sistem otak manusia. Sehingga potensi serta kapasitas otak itu sendiri bisa bekerja secara optimal, untuk menghasilkan subuah ide-ide dalam pelajaran yang sedang ia pelajari (Bahri Syaiful, 2010). Membaca lalu mencatat sebuat pelajaran.

\section{$\mathrm{C}=($ Connection $)$}

Koneksi keselarasan antara fakta atau bisa dikatakan dengan mengaitkan sebuah konsep dengan kenyataan lalu menghubungkan atau mengoneksikan hasi mind mapping dengan media alat pearaga.

$\mathrm{D}=$ (Discussion)

Diskusi merupakan suatu penguasaan isi pelajaran melalui wahana tukar pendapat berdasarkan pengetahuan dan pengalaman yang diperoleh guna memecahkan suatu masalah. Interaksi antara dua orang atau lebih/kelompok. Yang akhirnya akan memberikan rasa pemahaman yang baik dan benar dari dua atau lebih individu yang berinteraksi secara verbal dan dengan saling bertatap muka, tentang tujuan atau target yang telah diberikan dan diperoleh dengan cara pertukaran informasi atau mempertahankan pendapat (Usman, Uzer Moh, 2011).

\section{$\mathrm{E}=($ Evaluation $)$}

Evaluasi diartikan sebagai proses menentukan hasil yang dicapai dari beberapa kegiatan yang direncanakan untuk mendukung tercapainya tujuan pembelajaran (Arikunto, 2012).

Media atau sumber belajar adalah alat yang membantu dalam kegiatan belajar mengajar. Alat atau media ini dapat membantu mengatasi kesulitan siswa dalam memahami konsep dan juga dapat menjadi umpan balik baik dari siswa. Dengan memanfaatkan media, guru dapat membuat cara belajar siswa lebih menarik. Akan tetapi, dalam penggunaan media dalam proses pembelajaran, guru juga tidak boleh sembarangan, harus sesuai dengan tujuan yang hendak dicapai yaitu meningkatkan hasil belajar dan memelihara perhatian siswa terhadap proses belajar mengajar, memberikan 
motivasi dan mendorong siswa untuk belajar (Djamarah, 2006).

Berdasarkan hasil wawancara terhadap guru IPA terpadu kelas VIII B SMP 01 Islam Jember, ditemukan beberapa permasalahan seperti kurangnya semangat atau motivasi siswa dalam proses pembelajaran dan kurangnya keterlibatan siswa dalam proses pembelajaran. Akhirnya siswa menjadi kurang fokus dan kurang tertarik mendengarkan materi yang disampaikan guru. Sehingga hasil belajar IPA masih rendah. Nilai rata-rata hasil belajar siswa pra siklus yaitu 59 dengan ketuntasan klasikal 43\% sedangkan untuk mata pelajaran IPA nilai Kriteria Ketuntasan Minimal (KKM) yaitu 70, data yang diperoleh siswa diatas KKM hanya 10 siswa, sedangkan 13 siswa masih memperoleh nilai di bawah KKM.

Salah satu upaya untuk mengatasi permasalahan tersebut adalah dengan penggunaan model pembelajaran yang tepat yang dapat memotivasi siswa dalam proses pembelajaran agar materi yang disampaikan ke siswa dapat diterimah dengan baik. Salah satu model pembelajaran yang alternatif adalah model pembelajaran Reading Concept Map Connection Discussion Evaluation (RCCDE).

Peningkatan hasil belajar siswa dapat dilihat dari hasil belajar yang diperoleh. Berdasarkan uraian diatas maka telah dilakukan penelitian dengan judul: penerapan model RCCDE untuk meningkatkan hasil belajar siswa menggunakan alat peraga di SMP 01 Islam Jember.

\section{METODE PENELITIAN}

Penelitian ini dilakukan di kelas VIII B SMP 01 Islam Jember tahun ajaran 2019/2020 dengan jumlah siswa 23 siswa.
Penelitian ini dirancang menjadi 2 siklus, dimana pada setiap siklusnya meliputi langkah-langkah perencanaan, pelaksanaan, observasi dan pengumpulan data, dan refleksi.

Setelah mengetahui letak keberhasilan dan hambatan dari pelaksanaan untuk siklus pertama, maka peneliti menentukan rancangan dan mengevaluasi pembelajaran dari siklus pertama untuk proses penelitian di siklus kedua. Fungsi dari penelitian siklus kedua yaitu untuk lebih meyakinkan dan mengembangkan penelitian pada siklus pertama. Poses pelaksaan tindakan kedua sama dengan pelaksanaan di siklus pertama. Metode pengumpulan data diperoleh dari tes ulangan harian digunkan dengan tujuan untuk mengetahui proses pembelajaran Biologi dalam penerapan model RCCDE.

\section{PEMBAHASAN}

Model pembelajaran suatu perancang atau pola yang digunakan sebagai pedoman dalam pemecahan pembelajaran di dalam kelas atau pembelajaran di luar kelas sebagai faktor pendukung pembelajaran agar membuat siswa turut aktif dalam proses pembelajaran. Model pembelajaran adalah suatu cara yang dipergunakan oleh guru dalam mengadakan hubungan dengan siswa pada berlangsungnya pembelajaran, peran model pembelajaran sebagai alat untuk menciptakan proses mengajar dan belajar (Suprijono Agus, 2011).

Media atau sumber belajar adalah alat yang membantu dalam kegiatan belajar mengajar. Alat atau media ini dapat membantu mengatasi kesulitan siswa dalam memahami konsep dan juga dapat menjadi umpan balik baik dari siswa. Dengan memanfaatkan media, guru 
dapat membuat cara belajar siswa lebih menarik. Akan tetapi, dalam penggunaan media dalam proses pembelajaran, guru juga tidak boleh sembarangan, harus sesuai dengan tujuan yang hendak dicapai yaitu meningkatkan hasil belajar dan memelihara perhatian siswa terhadap proses belajar mengajar, memberikan motivasi dan mendorong siswa untuk belajar (Djamarah, 2006).

Peningkatan hasil belajar siswa menggunakan model RCCDE melalui media alat peraga materi sistem pernapasan manusia hasil belajar siswa pada siklus I dengan rata-rata hasil belajar siswa diperoleh nilai 76, sedangkan data hasil belajar siswa pada siklus II diperoleh rata-rata nilai hasil belajar siswa 81 yang berarti hasil belajar siswa biologi siswa kelas VIII B mengalami peningkatan 5\%. Kriteria semua siswa tuntas dalam memehami KKM 70.

Berdasarkan hasil tes ulangan harian dapat dinyatakan bahwa nilai rata-rata hasil belajar kongnitif mengalami peeningkatan. Hal tersebut juga di dukung oleh perbandingan hasil belajar siswa pra siklus, siklus I siklus II yang dapat dilihat dari grafik berikut ini:

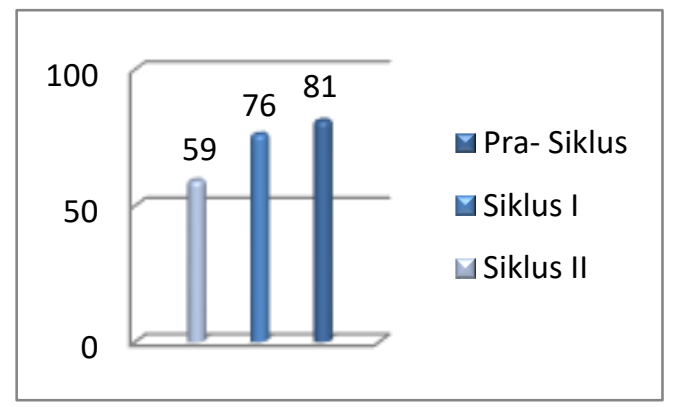

Gambar .1 Grafik Perbandingan Hasil Belajar Siswa

Gambar grafik diatas terlihat jelas bahwa setiap siklus dari pra siklus, siklus I, Siklus II mengalami peningkatan pada hasil belajar siswa. Hal ini menunjukkan model pembelajaran RCCDE memalui media alat peraga dapat meningkatkan hasil belajar siswa. Analisis hasil belajar sebelum menggunakan model pembelajaran RCCDE nilai rata-rata siswa didapat hasil 59, sedangkan pada siklus I didapat hasil 76 dan pada siklus II didapat hasil 81, setelah menggunakan model pembelajaran RCCDE hal tersebut dapat disimpulkan bahwa terjadi peningkatan hasil belajar siswa dengan menggunakan model pembelajaran RCCDE.

Maka penerapan model RCCDE sangat tepat untuk membantu keberhasilan proses pembelajaran. Hal ini sesuai dengan hasil peningkatan antara siklus I dengan siklus II sebesar 5\%. Penerapan model pembelajaran RCCDE memiliki sintak pembelajaran dengan tahapan Reading, Concept Map, Connection, Discussdion, Evaluation pada tahap Concept Map siswa diminta untuk membuat mind mapping lalu kemudian mind mapping tersebut di koneksikan dengan media alat peraga pada meteri sistem pernapasan. Hal tersebut juga didukung oleh hasil penelitian yang dilakukan, Mahanal (2014) hasil peneliti mengungkapkan bahwa penggunaan Reading Concept Map Student Teams Achievement Divisions pada kegiatan pembelajaran berpengaruh terhadap penguasaan konsep siswa menjadi lebih baik, sehingga dapat meningkatkan hasil belajar dan memperbaiki mutu pendidikan. Juga didukung oleh hasil penelitian yang dilakukan, Laili (2019) dengan judul " Pengaruh Model Pembelajaran RCCDE (Reading Concept Map Connection Discussion Evaluation) Terhadap Hasil Belajar Siswa dan Aktivitas Belajar siswa pada Pokok Bahasan Sistem Pernafasan pada Manusia Kelas VIII di 
MTs Al- Hidayah Karangharjo Silo". Terdapat perbedaan yang singnifikan antara kelas eksperimen dan kelas kontrol dalam hasil pembelajaran siswa, hal ini ditunjukkan dengan hasil uji paired sample test yang memiliki nilai $t_{\text {hitung }}>t_{\text {tabel }}\left(t_{\text {tabel }}\right.$ sebesar 2.091 pada pre test dan 6.304 pada post test $>1,714)$. Dengan demikian dapat disimpulkan bahwa $\mathrm{H}_{0}$ ditolok dan $\mathrm{H}_{\mathrm{a}}$ diterimah. Juga terdapat perbedaan yang signifikan singnifikan antara kelas eksperimen dan kelas kontrol dalam hasil pembelajaran siswa, hal ini ditunjukkan dengan hasil uji paired sample test yang memiliki nilai $t_{\text {hitung }}>t_{\text {tabel }}\left(t_{\text {tabel }}\right.$ sebesar 1.900 pada pre aktivitas belajar dan diperoleh thitung 8,179 pada post test aktivitas belajar siswa $>1,714$ ). Dengan demikian dapat disimpulkan bahwa $\mathrm{H}_{0}$ ditolok dan $\mathrm{H}_{\mathrm{a}}$ diterimah.

Kelebihan Model pembelajaran RCCDE model pembelajaran RCCDE ini sangat menarik perhatian siswa dalam pelaksanaan belajar dan dapat meningkatkan hasil belajar siswa, dimana dalam tahap pembelajaran menggunakan model pembelajaran RCCDE langkahlangkah kegiatan tersebut memiliki kelebihan sendiri-sendiri dalam kegiatan belajar yang dapat menarik semangat siswa dalam mengikuti pembelajaran, mengakibatka daya berfikir siswa berjalan dengan baik dan pengaruhnya terhadap pembelajaran dapat meningkatkan hasil belajar siswa dengan signifikan. Dapat memudahkan pemahaman siswa terhadap materi pembelajaran yang telah diberikan oleh peneliti dengan tahapan sintak pembelajaran Reading, Concept Map, Connection, Discussion, Evaluation siswa lebih mempunyai semangat dalam proses belajar, dengan tahapan membaca terlebih dahulu akan memudahkan pemahaman siswa terhadap materi pembelajaran sebelum pembelajaran dimulai. Penerapan model RCCDE siswa lebih terlihat aktif dalam mengikuti pembelajaran yang diberikan oleh peneliti, siswa lebih mudah memahami pembelajaran dengan bantuan media alat peraga media proses pernapasan manusia.

\section{KESIMPULAN}

Pembelajaran melalui penerapan model RCCDE melalui media alat peraga pada materi sistem pernapasan dapat meningkatkan hasil belajar siswa, hal tersebut dapat dibuktikan dengan hasil tes rata-rata nilai kognitif siswa pada siklus I dengan hasil 76 sedangkan pada siklus II mencapai 81, oleh karena itu peningkatan rata-rata nilai kognitif siswa dari siklus I ke siklus II mengalami peningkatan 5\%.

\section{DAFTAR PUSTAKA}

Anni, Chatarina Tri. 2006. Psikologi Belajar. Semarang: UPT UNNES Pres.

Arikunto, S. 2012. Dasar-dasar Evaluasi Pendidikan (Edisi 2). Jakarta : Bumi Aksara.

Arikunto, Suharsimi,et al. 204. Penelitian Tindakan Kelas. Jakarta: PT Bumi Aksara

Baedowi Ahmad, (2015). Calak Edu 3. Jakarta. PT Pustaka Alvaber. Biologi Siswa Kelas Xi Ipa 2 SMA Negeri 1 Pabelan Melalui Penerapan Model Project Based Learning.

Baedowi Ahmad, (2015). Calak Edu 3. Jakarta. PT Pustaka Alvaber. Biologi Siswa Kelas Xi Ipa 2 SMA Negeri 1 Pabelan Melalui Penerapan Model Project Based Learning.

Burhan.2013.Penelitian

Tindakan Kelas.Yogyakarta:Araska 
Djamarah, Syaiful Bahri. 2010. Startegi Belajar Mengajar. Jakarta: Asdi Mahasatya.

Laili, Fushilatul Ade. 2019." Pengaruh Model Pembelajaran RCCDE (Reading Concept Map Connection Discussion Evaluation) Terhadap Hasil Belajar Siswa pada Pokok Bahasan Sistem Pernafasan pada Manusia Kelas VIII di MTs Al- Hidayah Karangharjo Silo". Jember. Universitas Islam Jember.

Mahanal, S., Amirul Hasan \& Siti Zubaidah. 2014. " Implementasi Model Pembelajaran Reading Map Student Teams Achievement Division Untuk Meningkatkan Kemampuan Berfikir Kritis Dan Hasil Belajar Biologi Peserta Didik Kelas X Ipa Sma Insan Cendekia Shalahidin Malang". Jurnal, Pendidikan Biologi Pascasarjana Universitas Negeri Malang.

Nashar, Drs. 2004. Peran Motivasi dan Kemampuan awak dalam kegiatan Pembelajaran. Jakarta: Delia Press.

Rohadi, Aristo. 2003. Media Pembelajaran. Departemen Pendidikan Nasional, Jakarta.

Suprijono Agus.2011. Model-Modeln Pembelajaran. Jakarta: Gramedia Pustaka Jaya.

Widiatmoko dan S.D Pamelasari. 2012. Pembelajaran Berbasis Proyek Untuk Mengembangkan Alat Peraga IPA dengan Memanfaatkan Bahan Bekas Pakai. JPII. 1(1): 51-56.

Yensy, N.A. 2012. Penerapan Model Pembelajaran Kooperatif Tipe Examples Non Examples dengan Menggunkan Alat Peraga untuk Meningkatkan Hasil Belajar Siswa di Kelas VIII SMP N I Agramakmur. Jurnal Exacta, Vol.X No.1. 